\title{
Direct medical costs of motorcycle crashes in Ontario
}

\author{
Daniel Pincus MD, David Wasserstein MD MSc MPH, Avery B. Nathens MD MPH PhD, Yu Qing Bai MSc, \\ Donald A. Redelmeier MD MS(HSR), Walter P. Wodchis PhD
}

Cite as: CMAJ 2017 November 20;189:E1410-5. doi: 10.1503/cmaj.170337

Visual abstract available at www.cmaj.ca/lookup/suppl/doi:10.1503/cmaj.170337/-/DC1

\begin{abstract}
BACKGROUND: There is no reliable estimate of costs incurred by motorcycle crashes. Our objective was to calculate the direct costs of all publicly funded medical care provided to individuals after motorcycle crashes compared with automobile crashes.
\end{abstract}

METHODS: We conducted a populationbased, matched cohort study of adults in Ontario who presented to hospital because of a motorcycle or automobile crash from 2007 through 2013. For each case, we identified 1 control absent a motor vehicle crash during the study period. Direct costs for each case and control were estimated in 2013 Canadian dollars from the payer perspective using methodology that links health care use to individuals over time. We calculated costs attributable to motorcycle and automobile crashes within 2 years using a difference-in-differences approach.

RESULTS: We identified 26831 patients injured in motorcycle crashes and 281826 injured in automobile crashes. Mean costs attributable to motorcycle and automobile crashes were $\$ 5825$ and $\$ 2995$, respectively $(p<0.001)$. The rate of injury was triple for motorcycle crashes compared with automobile crashes (2194 injured annually/100000 registered motorcycles $v .718$ injured annually/100 000 registered automo- biles; incidence rate ratio [IRR] 3.1, 95\% confidence interval $[\mathrm{Cl}] 2.8$ to $3.3, p<$ 0.001 ). Severe injuries, defined as those with an Abbreviated Injury Scale $\geq 3$, were 10 times greater (125 severe injuries annually/100 000 registered motorcycles v. 12 severe injuries annually/100 000 registered automobiles; IRR $10.4,95 \% \mathrm{Cl} 8.3$ to $13.1, p<0.001$ ).

INTERPRETATION: Considering both the attributable cost and higher rate of injury, we found that each registered motorcycle in Ontario costs the public health care system 6 times the amount of each registered automobile. Medical costs may provide an additional incentive to improve motorcycle safety.
M otor vehicle safety has improved substantially over the past 100 years. ${ }^{1}$ Between 2000 and 2010, for example, deaths related to motor vehicle crashes decreased by $55.1 \%$ in 19 developed countries. ${ }^{1}$ In contrast, deaths and injuries among a subset of those injured in motor vehicle crashes - motorcycle crashes - remained stable during the same time period. ${ }^{2}$

Although medical costs may provide incentive to improve motorcycle safety, ${ }^{3-5}$ there is no reliable estimate of medical costs incurred by motorcycle crashes. Previous calculations of medical costs attributable to motorcycle crashes are limited to reviews of hospital charges at single centres. ${ }^{6}$ Estimates derived from these reviews are incomplete, neglecting costs incurred after a patient's discharge, for example. ${ }^{6-8}$

It is now possible to calculate patient-level medical costs in Ontario, Canada (population 13.6 million in 2014) with methodology that links publicly funded health care use to individuals over time. ${ }^{9}$
Using this methodology from the payer perspective, our objective was to calculate the direct costs of all publicly funded medical care provided to individuals who presented to hospital after motorcycle crashes compared with automobile crashes. We also examined the population incidence of injuries resulting from these crashes. Our hypothesis was that medical costs and injury rates attributable to motorcycle crashes, which can occur at high speeds and usually involve less personal protection, are significantly higher than those attributable to automobile crashes.

\section{Methods}

\section{Setting}

We conducted a population-based, matched cohort study in Ontario, Canada using linked health administrative databases at the Institute for Clinical Evaluative Sciences (ICES) (see Appendix 1, 
available at www.cmaj.ca/lookup/suppl/doi:10.1503/ cmaj.170337/-/DC2, Supplementary Appendix A - "data sources"). Medically necessary health care interactions, provider information and demographic characteristics of residents of Ontario are recorded in these databases. These data have previously been used to estimate medical costs ${ }^{10-15}$ and study traffic crashes. ${ }^{16-18}$

\section{Patients}

The study design is shown in Figure 1. Ontario residents who presented to the emergency department or were admitted to hospital after a motorcycle or automobile crash between Apr. 1, 2007 and Mar. 31, 2013 were eligible for inclusion. We used International Classification of Diseases, 10th Revision (ICD-10) codes to identify injured occupants of motor vehicles [motorcycle crash (V20-V29) and automobile crash (V40-V49, V50-V59, V70-V79), respectively]. ${ }^{19}$ We excluded non-Ontario residents and those who had previously presented to a hospital for a motor vehicle-related injury of any type within 2 years before the index date (see Appendix 1, Supplementary Appendix B "database codes").

For each motorcycle or automobile crash case, we identified 1 control from a representative subset of the Ontario population. The purpose of these controls was to determine baseline medical costs absent a motor vehicle crash and thus enable the calculation of incremental costs. Controls had health system contact but no documented motor vehicle-related injury during this time frame or dating back 2 years before the index date. Index dates for controls were randomly assigned based on the distribution of index dates for cases in the same fiscal year. Greedy matching occurred on age ( $\pm 90 \mathrm{~d})$, sex and the logit of a propensity score with a caliper of $0.2 \times$ standard deviation ${ }^{20-22}$ and was calculated based on patient comorbidity, income quintile and residential location (see "Covariates").

\section{Covariates}

We measured several covariates that have been shown to influence utilization of health care in Ontario. ${ }^{13}$ We analyzed age and sex as continuous and categorical variables, respectively.
Comorbidities listed on outpatient and hospital discharge abstracts in the 2 years before the index date were categorized according to collapsed aggregated diagnosis groups. ${ }^{23}$ Neighbourhood income quintile was used as a validated surrogate measure for socioeconomic status and social deprivation, by dissemination area. ${ }^{24-26}$ Patient location of residence was classified according to the Local Health Integrated Network and the Rurality Index of Ontario. ${ }^{27}$

\section{Outcomes}

The primary outcome of this study was direct medical costs within 2 years that were attributable to motorcycle and automobile crashes, and paid by Ontario's Ministry of Health and Long-Term Care. First, medical costs were calculated for each case and each control during each fiscal year of the study period using established patient-level costing methodology (see Appendix 1, Supplementary Appendix A). ${ }^{9}$ We then calculated costs attributable to motorcycle and automobile crashes within 2 years using a difference-in-differences approach: a baseline cost accrued the year before a crash was subtracted from costs in the first and second year after the crash (first difference) and then compared with the same difference among controls (second difference). ${ }^{28}$

We categorized costs as acute care hospital, including the emergency department, index admission, rehabilitation and any subsequent readmissions; physician; drugs and laboratory costs outside of hospitals; continuing care including residential longterm care and home care; and assistive devices. ${ }^{18}$ We divided care episodes that spanned more than 1 fiscal year on a pro rata basis. All costs were expressed as 2013 Canadian dollars using the health care component of the Ontario Consumer Price Index (www.statscan.gc.ca).

We included clinical data in secondary outcomes. First, the annual rates of those injured and dying (within $30 \mathrm{~d}$ ) from motorcycle and automobile crashes were reported, as long as the patient presented to hospital after the crash. We also compared more detailed clinical data between motorcycle and automobile crash cases. We identified the highest level of care required for

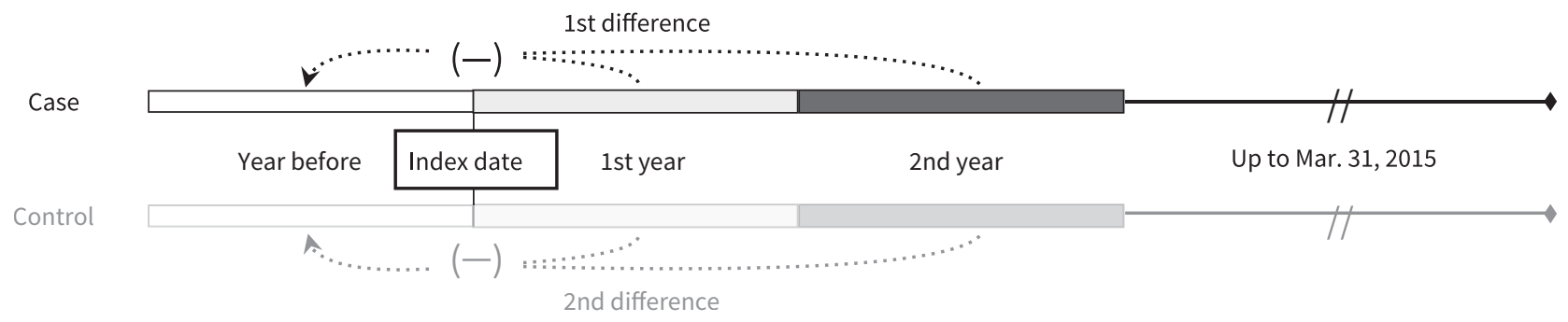

Figure 1: Depiction of the study design. For each case, we identified 1 control who had health system contact during the study period but no motor vehicle crash code. Index dates for controls were randomly assigned based on the distribution of index dates for cases in the same fiscal year. Costs attributable to motorcycle crashes and automobile crashes were then calculated using a difference-in-differences approach: the baseline cost accrued the year before the motorcycle or automobile crash was subtracted from costs in the 1st and 2nd year following the collision (1st difference) and then compared with the same difference among controls (2nd difference). 
each patient: emergency department visit only, or hospital admission, or admission to the intensive care unit (ICU). The Injury Severity Score (ISS) and Abbreviated Injury Scale (AIS) were used to assess injury severity. ISS and AIS were obtained from ICD-10 codes by means of a validated algorithm. ${ }^{29}$ Injury Severity Score was categorized as $<9,9-15,16-24$ or $\geq 25$. We defined "severe injuries" as those with an AIS $\geq 3$ and we reported them overall and for each anatomic region. The algorithm and operational definitions have been used previously in population-based research on administrative data in Ontario. ${ }^{30-32}$

\section{Statistical analysis}

We reported baseline characteristics of cases and controls as means and proportions and compared them using standardized differences ( $>0.1$ considered indicative of imbalance). ${ }^{33,34}$ We also compared characteristics between motorcycle crash cases and automobile crash cases using independent sample $t$ tests for continuous variables and $\chi^{2}$ tests for categorical variables. We also compared longer-term costs (up to $5 \mathrm{yr}$ ) between matched cases and controls who were enrolled before the 2011 fiscal year and for whom longer-term follow-up (> 2 yr) was available. We expressed annual rates of injuries and deaths per 100000 registered motorcycles or automobiles in the province using publicly available data from the Ministry of Transportation (see Appendix 1, Supplementary Appendix C). ${ }^{2}$ Incidence rate ratios (IRRs) with $95 \%$ confidence intervals ( $\mathrm{Cls}$ ) were then used to compare injury and death rates between motorcycle and automobile crash cases. We performed all analyses using SAS software (SAS version 9.3 and SAS Enterprise Guide version 6.1; SAS Institute) and set the type I error probability to 0.05 .

\section{Ethics approval}

The research protocol was approved by the Research Ethics Board at Sunnybrook Health Sciences Centre.

\section{Results}

\section{Descriptive clinical data}

We identified 26831 people in Ontario who were injured dur- ing the study period in motorcycle crashes and 281826 who were injured in automobile crashes. The annual incidence of injured persons was triple for motorcycle compared with automobile crashes (2194 injured annually/100 000 registered motorcycles $v$. 718 injured annually/100 000 registered automobiles; IRR 3.1, 95\% Cl 2.8 to 3.3, $p<0.001$; Table 1 ). Deaths (at $30 \mathrm{~d}$ ) were about 5 times greater (14 deaths annually/100 000 registered motorcycles $v .3$ deaths annually/100 000 registered automobiles; IRR 4.7, 95\% CI 2.9 to 7.6 , $p<0.001$; Table 1 ).

In terms of the level of care required for each patient, those injured in motorcycle crashes were significantly more likely to require admission to hospital and the ICU than those injured in automobile crashes (11.93\% v. $4.24 \%, p<0.001$ and $2.31 \%$ v. $1.09 \%, p<0.001$, respectively). Patients injured in motorcycle crashes were also more likely to have an ISS greater than 16 $(3.67 \%$ v. $1.32 \%, p<0.001)$ and have severe injuries $(5.69 \%$ v. $1.67 \%$ with AIS $\geq 3, p<0.001)$. Expressed per registered vehicle, severe injuries were 10 times greater for motorcycle crashes than automobile crashes (125 severe injuries annually/100 000 registered motorcycles v. 12 severe injuries annually/100 000 registered automobiles; IRR $10.4,95 \% \mathrm{Cl} 8.3$ to $13.1, p<0.001$ ). Severe injuries to the head, thorax, abdomen and extremities were all more common among patients injured in motorcycle than in automobile crashes (Table 2).

\section{Baseline characteristics after matching}

There were 26257 motorcycle crash cases and 276760 automobile crash cases ( $\cong 98 \%$ ) matched to controls. Covariates were balanced between cases and controls, with the exception that patients who had been in motorcycle crashes were more likely to reside in rural areas than controls. Baseline utilization of health care, as measured by costs in the previous year, was similar between cases and controls, which also indicated that groups were comparable (mean standardized difference [MSD] previous-year costs for motorcycle crash cases and controls were \$1779.76 [\$7003.45] and \$1664.34 [\$8732.5], MSD 0.02; automobile crash cases and controls \$2385.69 [\$8223.62] and \$2314.57 [\$9420.75], MSD 0.01).

\begin{tabular}{|c|c|c|c|c|c|c|c|}
\hline Crash type & 2007 & 2008 & 2009 & 2010 & 2011 & 2012 & Mean \pm SD \\
\hline \multicolumn{8}{|c|}{ No. of injuries } \\
\hline Motorcycle & 2568 & 2328 & 2212 & 2014 & 2105 & 1938 & $2194 \pm 230$ \\
\hline Automobile & 767 & 712 & 711 & 751 & 681 & 685 & $718 \pm 35$ \\
\hline \multicolumn{8}{|c|}{ No. of deaths } \\
\hline Motorcycle & 16 & 14 & 12 & 14 & 10 & 14 & $14 \pm 2$ \\
\hline Automobile & 3 & 3 & 3 & 3 & 2 & 3 & $3 \pm 0.4$ \\
\hline
\end{tabular}


The mean age of people (mean age \pm standard deviation 36.08 $\pm 16.34 \mathrm{yr}$ ) injured in motorcycle crashes was less than those injured in automobile crashes (mean age $38.53 \pm 19.09 \mathrm{yr}$ ) ( $p<$ 0.001). A greater proportion of patients who were in motorcycle crashes was also men ( $81 \%$ male) compared with patients who were in automobile crashes $(43 \%$ male) $(p<0.001)$. Other baseline characteristics and average costs among cases and controls after matching are presented in Appendix 1, Supplementary Appendix E.

\section{Patient-level costs of health care}

Mean costs for medical treatment attributable to motorcycle and automobile crashes within 2 years of the crash were $\$ 5825$ and $\$ 2995(p<0.001)$, respectively. Hospital costs for acute care accounted for more than $75 \%$ of this amount for both motorcycle and automobile crashes (Table 3). Furthermore, most costs were accrued within 1 year of the injury date. Attributable costs declined thereafter for both motorcycle and automobile crashes and remained stable and similar up to 5 years after the injury date (Appendix 1, Supplementary Appendix D).

\section{Interpretation}

In this population-based study of patients in the most populous Canadian province, we measured the cost of health care provided to patients who were injured in a motorcycle or automobile crash and required treatment at hospital. Mean costs for medical treatment attributable to motorcycle and automobile crashes within 2 years were $\$ 5825$ and $\$ 2995$, respectively. Because the annual number of injured persons per registered vehicle was triple and costs per injury were double for motorcycle crash victims versus automobile crash victims, we estimate the total cost to the universal health care system of injuries sustained in motor vehicles to be about 6 times greater per registered motorcycle than per automobile. Because acute care accounted for more than $75 \%$ of the costs, severe injuries (AIS $\geq 3$ ) that were 10 times greater for motorcycles than for automobiles likely accounted for the additional costs incurred by motorcycle crashes. All rates in our study could also be multiplied by 5 and expressed per kilometre travelled because the average automobile travels 5 times the distance of the average motorcycle (i.e., 15 times the injuries, 50 times the severe inju-

Table 2: Clinical outcomes among patients with motorcycle- and automobile-related injuries

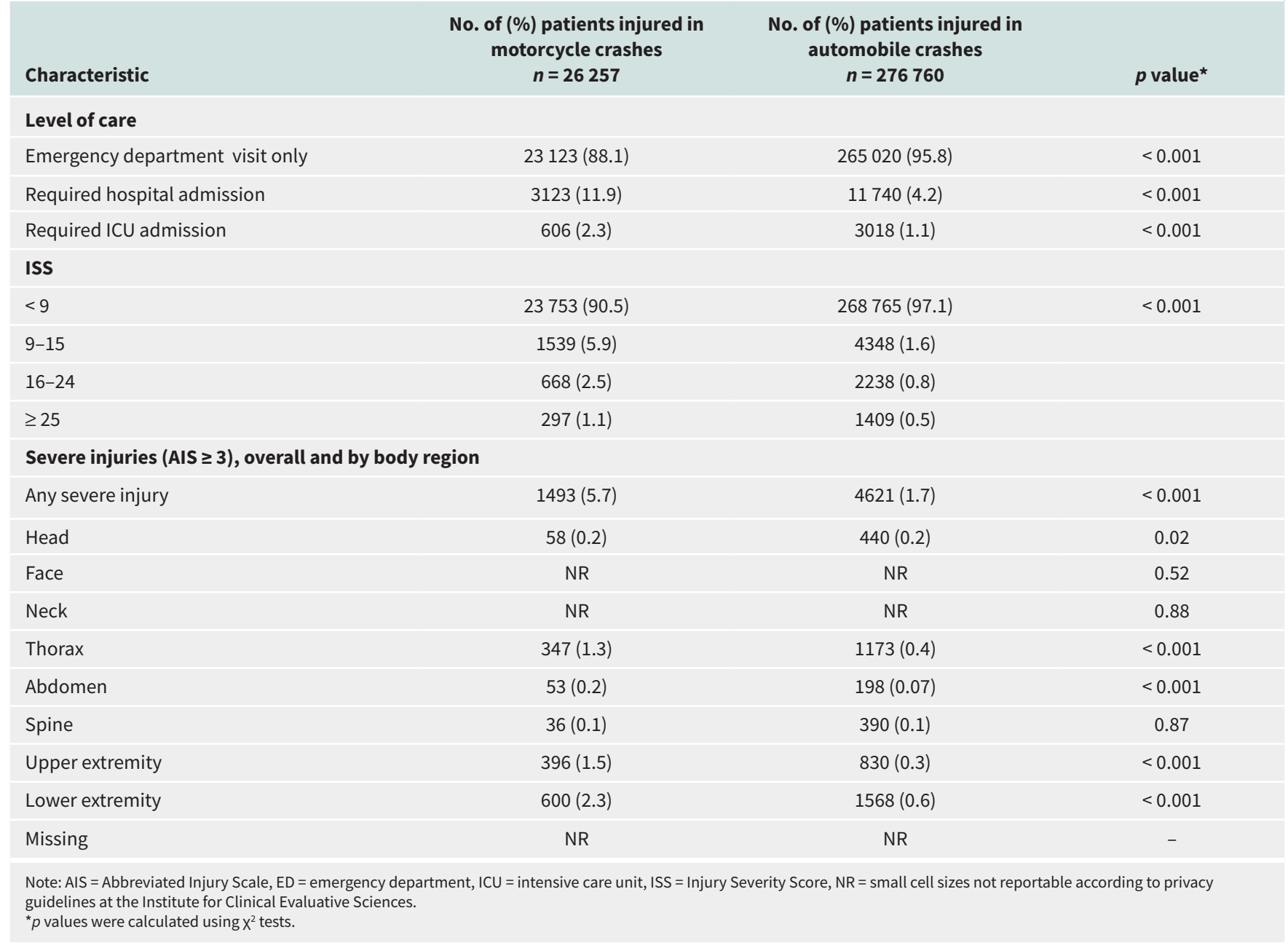


ries, 25 times the deaths, 30 times the costs per kilometre travelled). ${ }^{35}$

\section{Limitations}

Although our methodology captured most (an estimated 92\%) publicly funded health care costs provided to Ontario residents who were injured in motorcycle and automobile crashes, ${ }^{18}$ the most important limitation of our cost calculations was our inability to capture ongoing care costs for patients requiring outpatient rehabilitation, such as those with acquired brain injury. Accordingly, our cost calculations were less comprehensive over time as patients, and their care, were moved from the hospital setting and into the community. Because those involved in motorcycle crashes are considerably more likely to sustain head trauma ${ }^{8,36,37}$ and severe injuries in general, this limitation underestimated only costs attributable to motorcycle crashes compared with those costs incurred by automobile crashes (Table 2). Similarly, we also did not capture direct costs borne by private insurance, or indirect or opportunity costs incurred by individual patients and society. Indirect costs from missed workdays and permanent disability that precluded the ability to earn, for example, may also have been greater after motorcycle than automobile crashes, because motorcycle crash patients were younger and more severely injured.

Our data also do not include those injured or killed at the scene and who were not transported to hospital because we identified only patient encounters with health care providers. Because we identified only each patient's first event, it is also important to point out that injury rates reported in this study do not include subsequent crashes, if a patient had more than one.

\section{Implications}

We found that motorcycle injuries cost the public health care system 6 times more than automobile injuries, per vehicle. Expressed in other terms, Ontario's health care payer (the Ministry of Health and Long-Term Care) would expect to save $\$ 13.5$ million per year if collision rates remained unchanged and the province's registered motorcycles were replaced with automobiles. This estimate is likely conservative for several reasons mentioned previously (see "Limitations").

Despite publicly available data indicating that the risk associated with driving a motorcycle is much greater than that associated with driving an automobile, this knowledge has not translated to improvements in motorcycle safety. ${ }^{2,35}$ Medical costs may provide a novel financial incentive to mitigate the risk of motorcycle crashes. Anecdotally, insurance companies that raise their rates in response to private medical costs have already acted as a deterrent to motorcycle use. ${ }^{38}$ Health care costs incurred by the Ministry of Health and Long-Term Care in Ontario in treating patients involved in motor vehicle crashes (including motorcycle crashes) may be recovered, at least in part, by the Government of Ontario under the province's Insurance Act. This study provides an estimate of costs that may be recovered from motorcycle insurers under this legislation. The higher costs and greater incidence of severe injury and death we observed may also warrant other improvements to health prevention measures. For example, supplementary private health care insurance, an excise tax or another novel method of health coverage for motorcyclists may be justified with the goal of improving motorcycle safety.

We conducted our study at the level of a health care system that serves a population of about 13.6 million people. Although exact health care costs vary in other health care systems, the conclusions drawn from the relative comparison of motorcycle to automobile crashes we found in our study may be applicable beyond Canada to the rest of the developed world. For example, in a privately funded health care system, insurance companies and individual providers may accept a larger share of the direct health care costs than we have estimated in this study. We captured all hospital and physician costs provided in Ontario's publicly funded health care system.

\section{Conclusion}

We found that each motorcycle incurs 3 times the injuries, 6 times the medical costs and 5 times the deaths of each automobile. An understanding of these consequences may play a key role in public health strategy aimed at improving motorcycle safety. Future research is required to investigate indirect or opportunity costs incurred by motorcycle crashes.

Table 3: Cost attributable to a motorcycle- or automobile-related injury or death within 2 years

\begin{tabular}{|c|c|c|c|}
\hline Health care sector & $\begin{array}{c}\text { Mean cost attributable to } \\
\text { motorcycle crash, } 2013 \text { Can\$ } \\
(95 \% \mathrm{CI})\end{array}$ & $\begin{array}{l}\text { Mean cost attributable to } \\
\text { automobile crash, } 2013 \text { Can\$ } \\
(95 \% \mathrm{CI})\end{array}$ & $p$ value* \\
\hline Acute care hospital & 4409 (4247 to 4571$)$ & 2185 (1883 to 2340$)$ & $<0.001$ \\
\hline Physician & 1175 (1109 to 1241$)$ & 664 (534 to 731$)$ & $<0.001$ \\
\hline Continuing care & 224 (166 to 282 ) & $104(-16$ to 165$)$ & $<0.001$ \\
\hline Assistive devices & $14(-7$ to 25$)$ & $13(-32$ to 36$)$ & $<0.001$ \\
\hline Total cost & 5825 (5651 to 5999) & 2995 (2669 to 3161 ) & $<0.001$ \\
\hline
\end{tabular}




\section{References}

1. Sauber-Schatz EK, Euerer DJ, Dellinger AM, et al. Vital signs: motor vehicle injury prevention - United States and 19 comparison countries. MMWR Morb Mortal Wkly Rep 2016;65:672-7.

2. Ontario road safety: annual report 2013. Toronto: Ministry of Transportation; 2013.

3. Chaloupka F. Rational addictive behavior and cigarette-smoking. J Polit Econ 1991;99:722-42.

4. Gilmore AB, Tavakoly B, Taylor G, et al. Understanding tobacco industry pricing strategy and whether it undermines tobacco tax policy: the example of the UK cigarette market. Addiction 2013;108:1317-26.

5. Jha P, Chaloupka FJ. The economics of global tobacco control. BMJ 2000;321:358-61.

6. Costs of injuries resulting from motorcycle crashes: a literature review. Washington: National Highway Traffic Safety Administration; 2003. Available: www.nhtsa.gov/ people/injury/pedbimot/motorcycle/Motorcycle_HTML/overview.html (accessed 2017 Apr. 27)

7. Dobson JL. The public cost of motorcycle trauma. JAMA 1989;261:1149.

8. Monk JP, Buckley R, Dyer D. Motorcycle-related trauma in Alberta: a sad and expensive story. Can J Surg 2009;52:E235-40.

9. Wodchis W, Bushmeneva K, Nikitovic M, et al. Guidelines on person-level costing using administrative databases in Ontario. Working Paper Series Vol. 1. Toronto: Health System Performance Research Network; 2013.

10. Chen A, Bushmeneva K, Zagorski B, et al. Direct cost associated with acquired brain injury in Ontario. BMC Neurol 2012;12:76.

11. Nikitovic M, Wodchis WP, Krahn MD, et al. Direct health-care costs attributed to hip fractures among seniors: a matched cohort study. Osteoporos Int 2013; 24:659-69.

12. Munce SEP, Wodchis WP, Guilcher SJT, et al. Direct costs of adult traumatic spinal cord injury in Ontario. Spinal Cord 2013;51:64-9.

13. Rosella LC, Fitzpatrick T, Wodchis WP, et al. High-cost health care users in Ontario, Canada: demographic, socio-economic, and health status characteristics. BMC Health Serv Res 2014;14:532.

14. Tanuseputro P, Wodchis WP, Fowler R, et al. The health care cost of dying: a population-based retrospective cohort study of the last year of life in Ontario, Canada. PLoS One 2015;10:e0121759.

15. Rosella LC, Lebenbaum M, Fitzpatrick T, et al. Impact of diabetes on healthcare costs in a population-based cohort: a cost analysis. Diabet Med 2016;33:395-403.

16. Redelmeier DA, Katz D, Lu H, et al. Roadway crash risks in recent immigrants. Accid Anal Prev 2011;43:2128-33.

17. Redelmeier DA, May SC, Thiruchelvam D, et al. Pregnancy and the risk of a traffic crash. CMAJ 2014;186:742-50.

18. Bai YQ, Santos G, Wodchis WP. Cost of public health services for Ontario residents. Applied Health Research Question Series. Toronto: Health System Performance Research Network; 2016.

19. Juurlink D, Preyra C, Croxford R, et al. Canadian Institute for Health Information Discharge Abstract Database: a validation study. Toronto: Institute for Clinical Evaluative Sciences; 2006.

20. Austin PC. Comparing paired vs non-paired statistical methods of analyses when making inferences about absolute risk reductions in propensity-score matched samples. Stat Med 2011;30:1292-301.
21. Austin PC. An introduction to propensity score methods for reducing the effects of confounding in observational studies. Multivariate Behav Res 2011;46:399-424.

22. Austin PC. Optimal caliper widths for propensity-score matching when estimating differences in means and differences in proportions in observational studies. Pharm Stat 2011;10:150-61.

23. Weiner JP, Abrams C. The Johns Hopkins ACG ${ }^{\circledR}$ System: technical reference guide, version 10.0. Baltimore: Johns Hopkins University; 2011.

24. Agabiti N, Picciotto S, Cesaroni G, et al.; Italian Study Group on Inequalities in Health Care. The influence of socioeconomic status on utilization and outcomes of elective total hip replacement: a multicity population-based longitudinal study. Int J Qual Health Care 2007;19:37-44.

25. Santaguida PL, Hawker GA, Hudak PL, et al. Patient characteristics affecting the prognosis of total hip and knee joint arthroplasty: a systematic review. Can J Surg 2008;51:428-36.

26. Matheson FI, Moineddin R, Dunn JR, et al. Urban neighborhoods, chronic stress, gender and depression. Soc Sci Med 2006;63:2604-16.

27. Kralj B. Measuring "rurality" for purposes of health care planning: an empirical measure for Ontario. Toronto: Ontario Medical Association; 2005.

28. Dimick JB, Ryan AM. Methods for evaluating changes in health care policy: the difference-in-differences approach. JAMA 2014;312:2401-2.

29. Haas B, Xiong W, Brennan-Barnes M, et al. Overcoming barriers to populationbased injury research: development and validation of an ICD-10-to-AIS algorithm. Can J Surg 2012;55:21-6.

30. Haas B, Stukel TA, Gomez D, et al. The mortality benefit of direct trauma center transport in a regional trauma system: a population-based analysis. $J$ Trauma Acute Care Surg 2012;72:1510-5, discussion 1515-7.

31. Gomez D, Haas B, de Mestral C, et al. Gender-associated differences in access to trauma center care: a population-based analysis. Surgery 2012;152:179-85.

32. Gomez D, Haas B, de Mestral C, et al. Institutional and provider factors impeding access to trauma center care: an analysis of transfer practices in a regional trauma system. J Trauma Acute Care Surg 2012;73:1288-93.

33. Austin PC. Balance diagnostics for comparing the distribution of baseline covariates between treatment groups in propensity-score matched samples. Stat Med 2009;28:3083-107.

34. Normand ST, Landrum MB, Guadagnoli E, et al. Validating recommendations for coronary angiography following acute myocardial infarction in the elderly: a matched analysis using propensity scores. J Clin Epidemiol 2001;54:387-98.

35. Traffic safety facts 2015: a compilation of motor vehicle crash data from the fatality analysis reporting system and the general estimate system. Washington: National Highway Traffic Safety Administration; 2016. Available: https:// crashstats.nhtsa.dot.gov/Api/Public/ViewPublication/812384 (accessed 2017 Apr. 27).

36. Keng SH. Helmet use and motorcycle fatalities in Taiwan. Accid Anal Prev 2005;37:349-55.

37. Hotz GA, Cohn SM, Mishkin D, et al. Outcome of motorcycle riders at one year post-injury. Traffic Inj Prev 2004;5:87-9.

38. Harvey I. Motorcycle rates rising with severity, number of claims. Toronto Star 2016 May 28. Available: https://www.thestar.com/autos/2016/05/28/motorcycle-rates -rising-with-severity-number-of-claims.html (accessed 2017 Apr. 27).

\section{Competing interests: None declared.}

This article has been peer reviewed.

Affiliations: Department of Surgery (Pincus, Wasserstein, Nathens), Division of Orthopaedic Surgery, University of Toronto; Institute for Clinical Evaluative Sciences (Pincus, Nathens, Bai, Redelmeier, Wodchis); Institute of Health Policy, Management and Evaluation (Pincus, Nathens, Bai, Redelmeier, Wodchis), University of Toronto; Department of Surgery (Wasserstein, Nathens) and Division of General Internal Medicine (Redelmeier), Sunnybrook Health Sciences Centre; Centre for Leading Injury Prevention Practice Education \& Research (Redelmeier), Toronto, Ont.

Contributors: All of the authors contributed to the conception and design of the study; acquired, analyzed and interpreted the data; drafted and revised the manuscript, approved the final version to be published and agreed to be accountable for all aspects of the work.

Funding: This research was supported by grants from the Ontario Ministry of Health and Long-Term Care (MOHLTC) and the Ontario Strategy for Patient-Oriented Research (SPOR) Support Unit to the Health System Performance Research Network (HSPRN: fund no. 06034, recipient WPW), and by the Institute for Clinical Evaluative Sciences (ICES), which is also funded by an annual grant from the MOHLTC. The funders had no role in study design, data collection and analysis, decision to publish or preparation of the manuscript. Parts of the material are based on data and information compiled and provided by the Canadian Institute for Health Information (CIHI). No endorsement by ICES, the MOHLTC or $\mathrm{ClHI}$ is intended or should be inferred. No benefits have been received or will be received from a commercial party related directly or indirectly to the subject of this article.

Acknowledgements: The authors would like to acknowledge Allan S. Detsky for providing comments on an earlier version of the manuscript.

Disclaimer: This study was supported by ICES, which is funded by an annual grant from MOHLTC. The opinions, results and conclusions reported in this paper are those of the authors and are independent from the funding sources. No endorsement by ICES or the Ontario MOHLTC is intended or should be inferred.

Accepted: July 17, 2017

Correspondence to: Daniel Pincus, d.pincus@utoronto.ca 